Int. J. Dev. Biol. 58: 917-927 (2014)

doi: $10.1387 / \mathrm{ijdb} .150053 \mathrm{cr}$

\title{
The importance of cartilage to amphibian development and evolution
}

\author{
CHRISTOPHER S. ROSE* \\ James Madison University, Harrisonburg, VA, USA
}

\begin{abstract}
The duality of amphibians is epitomized by their pharyngeal arch skeletons, the larval and adult morphologies of which enable very different feeding and breathing behaviors in aquatic and terrestrial life. To accomplish this duality, amphibian pharyngeal arch skeletons undergo two periods of patterning: embryogenesis and metamorphosis, and two periods of growth: larval and postmetamorphic. Their extreme ontogenetic variation, however, is coupled with relatively limited phylogenetic variation. I propose that amphibians face an evolutionary tradeoff between their ontogenetic and phylogenetic diversification that stems from the need to grow and transform the pharyngeal arch skeleton in cartilage rather than bone. Cartilage differs fundamentally from bone in its histology, function, development and growth. Cartilage is also the first skeletal tissue to form embryonically and provides more cellular pathways for shape change than bone. This article combines morphological, histological and experimental perspectives to explore how pharyngeal arch cartilage shape is controlled in amphibian embryogenesis, growth and metamorphosis, and how amphibian skeletal ontogenies are impacted by using cartilage to evolve a complex life cycle and in evolving away from a complex life cycle.
\end{abstract}

KEY WORDS: Amphibian, cartilage, metamorphosis, evo-devo, pharyngeal arch skeleton

\section{Introduction}

Vertebrates typically form most of their embryonic skeleton in cartilage and soon cover or replace much of it with dermal and endochondral bone (de Beer, 1937, Goodrich, 1930). Thus, the embryonic patterning of skeleton primarily involves mesenchymal cells condensing to form cartilage and the postembryonic growth of skeleton involves primarily bone. In accordance with von Baer, embryonic patterning generally appears to account for the big phylogenetic differences in skeletal morphology and postembryonic growth for smaller phylogenetic differences. Amphibians depart from this general vertebrate program in several important ways. They have two periods of patterning: embryogenesis and metamorphosis, and two periods of growth: larval and postmetamorphic, which collectively produce very disparate larval and adult morphologies. Their pharyngeal arch (PA) skeletons, which represent the mobile part of the skull and support different feeding and breathing behaviors in the two growth environments, persist largely or entirely as cartilage throughout larval growth and metamorphosis. Amphibians have also repeatedly evolved away from (and possibly even re-evolved) their primitively complex life history, but with relatively little divergence from or innovation in their larval and adult PA skeletons (Rocek, 2003, Rose, 2003). More generally, despite the extremely specialized bauplan of frogs (Handrigan and Wassersug, 2007), amphibians simply cannot hold a candle to the diversities in adult skeleton that have been attained by chondrichthyans, teleosts, reptiles, birds and eutherian mammals (Alexander, 1994, Winchester, 2012).

These features place amphibians on a unique pedestal for evolutionary developmental morphologists. Understanding how their ontogenetic variation in PA skeletal shape impacts their phylogenetic variation requires assessing the relative contributions of all four phases of patterning and growth to skeletal shape trajectories. It also requires working out the mechanisms that regulate skeletal shape during these phases and how they might constrain the evolution of shape trajectories. More specifically, cartilage differs fundamentally from bone in its histology, function, development and growth, and its prevalence in the feeding and breathing skeleton of larval and metamorphic-stage amphibians is not likely coincidental nor without consequence for amphibian evolution. This article explores the development and evolution of the

Abbreviations used in this paper: PA, pharyngeal arch.

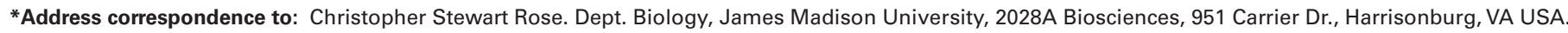
Tel: 540-568-6666. Fax: 540-568-3333. E-mail: rosecs@jmu.edu - web: http://www.jmu.edu/biology/people/all-people/faculty/faculty-rose.shtml
}

Accepted: 4 December 2014.

ISSN: Online 1696-3547, Print 0214-6282 
A

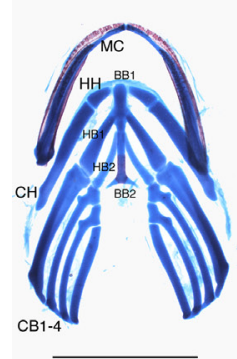

B

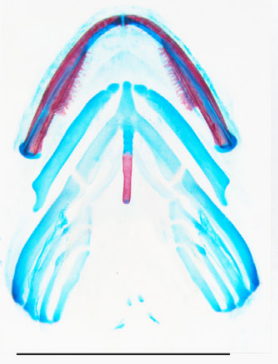

C

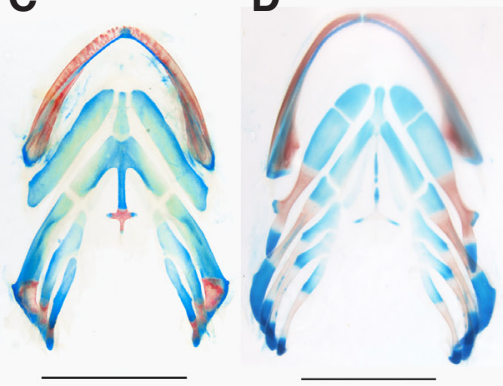

E

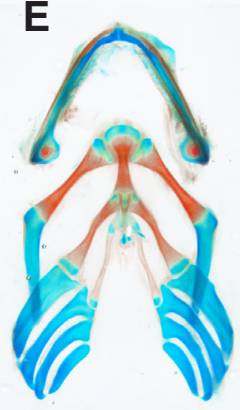

F

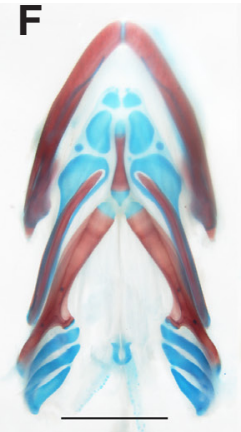

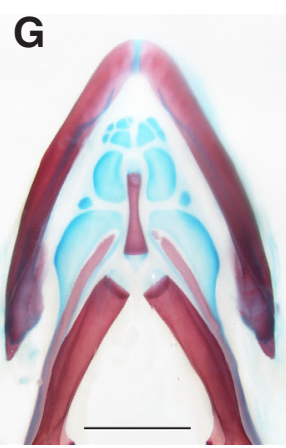

Fig. 1. Ventral views of the dissected, skeletally stained pharyngeal arch skeletons of larval stage salamanders. Blue is cartilage, red is bone, scale bars are $5 \mathrm{~mm}$. (A) Ambystoma jeffersonianum; (B) Notophthalmus viridescens; (C) Gyrinophilus porphyriticus; (D) Dicamptodon ensatus; (E) Siren intermedia; (F) Amphiuma means; (G) closeup of the anterior skeleton from a larger specimens of Amphiuma means. BB1-2, first and second basibranchial (the latter is also referred to as a urohyal); CB 1-4, larval ceratobranchials; CH, ceratohyal; HB1-2, first and second hypobranchials; HH, hypohyal; MC, Meckels cartilage (which is lined or encased in dermal bone). All specimens are in the personal collections of the author, John Reiss provided the specimen for (D).

amphibian pharyngeal arch skeleton with the aim of encouraging a whole-ontogeny, cartilage-specific approach for understanding how skeletal shape evolves in one class of vertebrates. The focus is explicitly at a cell and tissue level on the premise that while genes control cell behaviors and genetic changes make permanent evolutionary changes, tissue-level properties and ontogenetic patterns are ultimately what inform us most about mechanisms of evolutionary diversification.

\section{The functional morphology of the amphibian pharyngeal arch skeleton}

Although a descriptive survey of the diversity in amphibian PA skeletons is far beyond the scope of this review and recent ones are available elsewhere (Cannatella, 1999, Pugener et al., 2003, Rocek, 2003, Rose, 2003), a brief overview is helpful here to establish context. Larval amphibian PA skeletons consist of flexible networks of rods and bars that are connected to each other by moveable articulations and branchiomeric and hypobranchial muscles (Fig. 1-2). The network is generally designed to pump water through the buccal, pharyngeal and branchial chambers and for biting, sucking or rasping anteriorly and supporting internal or external gills posteriorly (Cannatella, 1999, Deban, 2003, Deban and Wake, 2000). Whereas jaw and jaw suspension cartilages are specialized for different feeding behaviors in tadpoles (see below), they are relatively unspecialized in larval salamanders; the lower jaw cartilage is oriented horizontally and gently curved and the jaw suspension cartilage (palatoquadrate) is oriented close to vertical. The hyoid and branchial arch elements of both groups tend to be straight or gently curving bars that run parallel with each other. The palatoquadrate has multiple connections to the chondrocranium that change during metamorphosis and the lateral end of the hyoid cartilage is usually tethered by muscle or ligament to the jaw suspension or chondrocranium. Although central portions of elements often mineralize (whether by calcification, endochondral replacement or periosteal ossification has not been well investigated), the majority of the skeleton including articulations persists as cartilage until the end of metamorphosis. Larval salamanders supplement their first arch cartilages with dentigerous dermal jaw and palate bones that participate in prey capture and intraoral transport of food (Fig. 1). The upper and lower jaws of tadpoles consist primarily of cartilage that defines their shape and function until metamorphosis (Fig. 2), at which point dermal bones replace the upper jaw cartilages and fully encase the lower jaw cartilage.

Compared to their larval counterparts, the hyoglossal skeletons of metamorphosed salamanders consist of fewer, more tapered bars and rods arranged in a more mobile network that supports the tongue base anteromedially and collapses towards the midline as the tongue is protruded or projected (Fig. 4F, Deban, 2003, Rose, 2003, Wake and Deban, 2000). The hyoglossal skeletons of frogs, in contrast, consist of a variable combination of bar-, rod- and plate-like elements that are separate laterally but coelesce medially in an immobile platform (Fig. 1 in Rose, 2009, Rocek, 2003). They function in supporting the tongue and larynx and in tongue
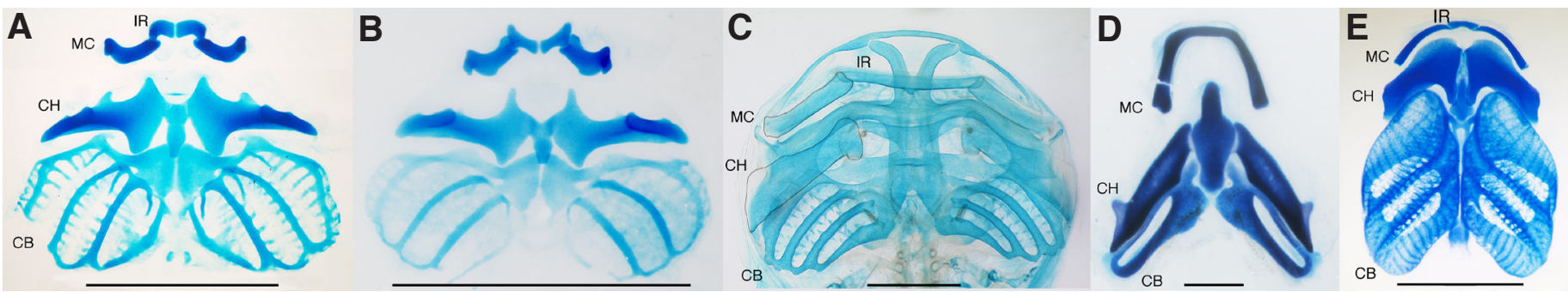

Fig. 2. Ventral views of the dissected, skeletally stained pharyngeal arch skeletons of larval stage frogs. Blue is cartilage, red is bone, scale bars are $5 \mathrm{~mm}$, except for (D) which is $1 \mathrm{~mm}$; lines in (C) show outlines of poorly stained MC and CH. (A) Lithobates sylvaticus (Rana sylvatica); (B) Anaxyrus (Bufo) americanus; (C) Lepidobatrachus laevis; (D) Hymenochirus boettgeri; (E) Xenopus laevis. IR, infrarostral; see Fig. 1 for other terms. All specimens except (C) are in the personal collections of the author; Carlos Infante provided the photo for (C) and David McLeod provided the specimen for (D). 
protrusion in forms with tongues and in suction feeding in forms without them (Carroño and Nishikawa, 2010, Nishikawa, 2000). Amphibians with lungs also use their larval and adult PA skeletons to pump air for lung ventilation.

The replacement of cartilage by bone (or calcification of cartilage) in larval and adult PA skeletons is usually limited to the central portions of rods and plates, and often in regions that are expected to receive maximal loading, e.g., the recurved distal portion of the adult ceratohyal in plethodontid salamanders (Fig. $4 \mathrm{~F}$ ), which anchors the tongue during its projection, and the distal portions of larval ceratobranchials in large salamanders, which support external gills (Fig. $1 \mathrm{C}-\mathrm{D}$ ). Indeed, the one metamorphosing plethodontid to exhibit the latter ossifications has the largest larvae in this family and other salamanders that exhibit them tend to grow larger larvae (Rose, 1995a, Rose, 2003). The lower jaw cartilage also acquires endochondral ossifications at one or both ends. Judging by anatomical descriptions, the increase in diameter of parts of elements that have been replaced by bone often lags behind that of adjacent cartilage (Fig. 1 D-E). However, elements that are largely or entirely replaced by bone, e.g., the adult ceratohyal in Hymenochirus (Ridewood, 1899) and the first branchial arch skeleton in Amphiuma (Fig. 1F), appear to grow proportionally with other parts of the PA skeleton.

\section{How do embryonic patterning and growth contribute to amphibian pharyngeal arch skeletal shape?}

Thanks to developmental geneticists, we have a fairly detailed picture of how the pharyngeal arch skeleton is patterned embryonically. Depending on their axial level in the neural fold, cranial neural crest cells initiate one of several different homeotic gene-initiated cascades of gene expression. These cascades are maintained and elaborated upon as the cells migrate into pharyngeal arches (Fig. $3 \mathrm{~A}-\mathrm{C}$ ) by signaling proteins coming from the neural tube, pharyngeal ectoderm, somitomere-derived arch mesenchyme and pharyngeal endoderm (Depew et al., 2002, Miller et al., 2003, Pasqualetti et al., 2000, Santagati and Rijli, 2003, Square et al.,
2015). The cranial neural crest cells of amphibians migrate beneath the pharyngeal ectoderm and then move deep to temporarily encase the arch mesenchyme (Cerny et al., 2004). Cells close to the pharyngeal endoderm condense into PA skeletal rudiments (Fig. 3 D-G) while others presumably mingle with the arch mesenchyme to form muscle linings and connections to skeleton (Ericsson et al., 2004, Olsson and Hanken, 1996, Sadaghiani and Thiébaud, 1987). Anterior-posterior differences in cell position are preserved from the neural fold all the way through migration to condensation (Olsson and Hanken, 1996).

As the early parts of the gene cascades are largely conserved among vertebrates (Square et al., 2015), the species-specific shapes and sizes of PA condensations appear to be determined by downstream interactions between the gene cascades and signal proteins that control neural crest cell behaviors during and after crest cell migration. While this interaction has not been worked out for amphibians, shaping of the mandibular arch condensations in birds into bills and beaks of different shapes involves postmigration cell division being regulated in a species-specific manner by BMP and calmodulin signaling (Abzhanov et al., 2006, Abzhanov et al., 2004, Wu et al., 2006, Wu et al., 2004).

Interestingly, first and second arch neural crest cells transplanted homotopically between frog and salamander embryos and between duck and quail embryos still develop cartilages with donor-specific shapes and sizes (Andres, 1949, Schneider and Helms, 2003, Tucker and Lumsden, 2004, Wagner, 1949, Wagner, 1955). These include the infrarostral cartilage, which forms as a separate cartilage in the median lower jaw of larval frogs, is unique to frogs, and continues to form when frog first arch cells are transplanted into salamander embryos. These transplants collectively suggest that most species-specific aspects of cartilage shape are instructed by downstream gene expression that is autonomous to crest cells and not by the signaling or topography of arch tissues. Also, although formation of the jaw joint (the joint between Meckels cartilage and the palatoquadrate) and the anterior-posterior orientation of PA cartilages requires signals from arch tissues (Miller et al., 2003, Pasqualetti et al., 2000), the signals act permissively in these
A

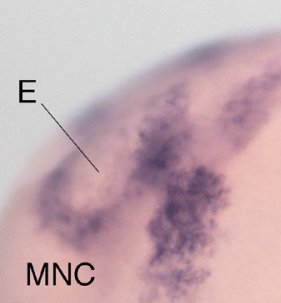

HNC

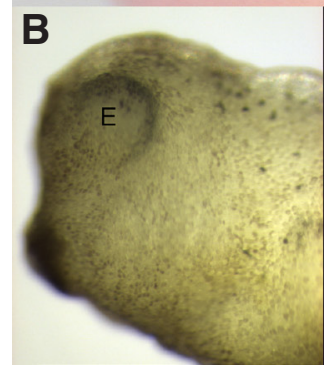

aBNC
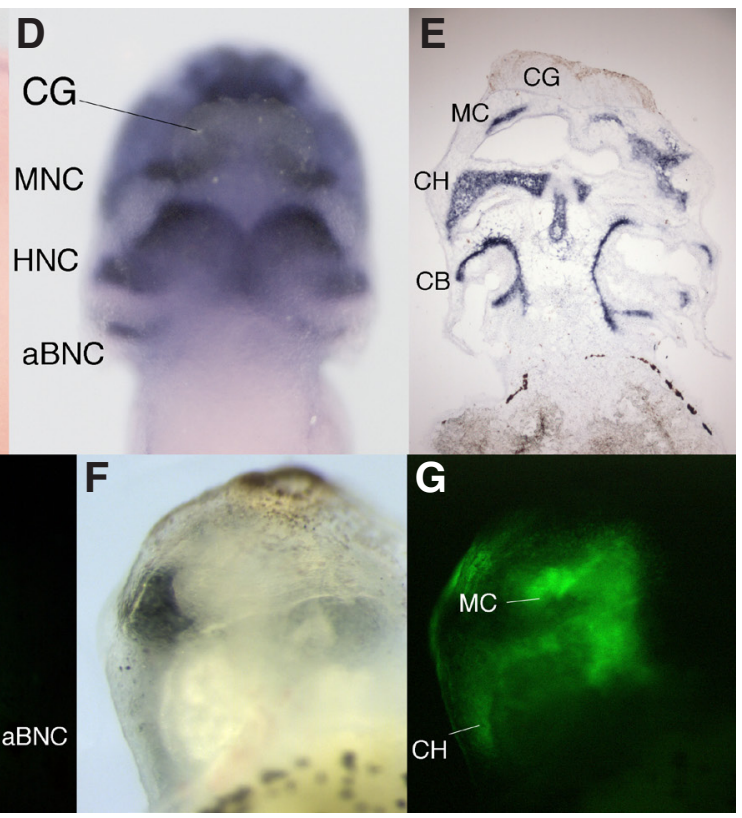

Fig. 3. Neural crest cell migration and differentiation in the frog Xenopus laevis. (A) Lateral view of whole mount in situ hybridization with a probe for the neural crest marker Sox9 that shows migration of mandibular and hyoid arch neural crest cells (MNC, HMC) at Nieuwkoop Faber (NF) stage 20. (B,C) Lateral views of transplanted green florescent protein (GFP)-expressing neural crest showing migration of MNC, HNC and anterior branchial neural crest cells (aBNC) at NF stage 34; (D) ventral view of Sox9 whole mount in situ hybridization at NF 39 showing MHC, HNC and aBNC condensations; (E) Sox9 in situ hybridization of frontal section at NF 41 showing $M C, C H$ and $C B$ condensations; $(\mathbf{F}, \mathbf{G})$ ventral views of same GFP-transplant as in (B) showing $\mathrm{MC}, \mathrm{CH}$ and $C B$ condensations at NF 41. E, eye rudiment; $C G$, cement gland; see Fig. 1 for other terms. Tyler Square provided figures $(A, D)$; all others were prepared by the author. 
respects and their input to lower jaw development is conserved, at least within vertebrate classes. In contrast, formation of the intramandibular joint (the joint between the infrarostral and Meckels cartilage) in frogs appears to be autonomous to frog neural crest cells and its occurrence in Xenopus appears to involve shifts in the expression of one or two downstream transcription factors that allow cells to form this joint (Square et al., 2015). This difference raises the intriguing possibility that the phylogenetic history of PA skeletal joints (and thus PA cartilage homologies) is preserved in the genetic machinery for joint formation and that more recently evolved joints can be distinguished by autonomous specification involving later acting transcription factors.

How has the embryonic patterning of PA skeletons evolved within salamanders and frogs? Changes in salamanders include the recurring loss of hypohyals (Fig. 1C), fourth ceratobranchials (Fig. 1C), and second basibranchial cartilages, fusions between elements within the same arch, and changes in the relative size of elements (Rose, 2003). This paper follows the hypobranchial, ceratobranchial terminology of Rose 2003, as there is no evidence for the loss of hypobranchials in the ancestral salamander, which is implied by the alternative terminology of ceratobranchial, epibranchial. Functionally significant changes in cartilage size and shape are relatively rare and the most dramatic examples are associated with animals escaping complex life cycles by evolving direct development and paedomorphosis (see below). Losses and fusions and changes in relative size of cartilages are consistent with changes in neural crest migration and joint formation. For example, the fourth ceratobranchial has been lost repeatedly and in the forms in which it is variably present (Hemidactylium, Pseudobranchus), it is often partially or totally fused with the third ceratobranchial (Rose, 2003). Since the neural crest cells that form the third and fourth ceratobranchials migrate as part of one large stream at least until the cells move deep to get to endoderm (Cerny et al., 2004, Falck et al., 2002, Sadaghiani and Thiébaud, 1987), fusion or loss of the fourth ceratobranchial could result from a minor change in migration pathway. The hypohyal, which has also been lost repeatedly, varies considerably in size relative to the ceratohyal in the forms that have it and its separation from the ceratohyal is delayed to mid larval stages in at least one hynobiid (Rose, 2003). Also, a plethodontid salamander that lacks the hypohyal at larval stages (Fig. 4 A-C) can be induced by exogenous thyroid hormone to develop the tongue-supporting lingual cartilage in continuity with the ceratohyal (Rose, 1995c, Rose, 2003). This suggests that plethodontids have delayed formation of the joint that separates the hypohyal from the ceratohyal to metamorphosis, at which point the hypohyal emerges as the lingual.

In contrast to larval salamanders, tadpoles rarely exhibit loss or fusion of PA elements but show great variation in the shape, size and position of first, second and third arch cartilages, which reflects specialization for different foods and feeding behaviors. For example, a long, almost horizontal palatoquadrate and similarly sized but differentially aligned infrarostral and Meckels cartilages correlates with rasping vegetation and microphagy (Fig. $2 \mathrm{~A}-\mathrm{B}$, de Jongh, 1968, Pusey, 1938); an oversized, robust lower jaw with an unpaired infrarostral correlates with carnivory by megalophagy (Fig. 2C, Ziermann et al., 2013); an elongated, U-shaped lower jaw without a distinct infrarostral, loss of the posterior two ceratobranchials, and an expanded basihyal correlates with carnivory by suction feeding (Fig. 2D, Deban and Olson, 2002, Ericsson et al., 2009) and a slender lower jaw comprised mostly of Meckels cartilage plus a robust ceratohyal and overdeveloped ceratobranchials correlates with midwater suspension feeding (Fig. 2E, Ryerson and Deban, 2010, Sedra and Michael, 1957).

Variation in the shape, size and position of larval PA cartilages begs the question of how much arises in embryonic patterning and how much emerges in postembryonic growth? The options for postembryonic growth are isometry (which is used here to mean no change in shape with size) and allometry, which usually means that dimensions for describing shape adhere to an exponential growth equation but can include any deviation from nonisometric growth. Though anatomical descriptions of PA skeletal ontogeny do not usually quantify shape or variation therein, comparisons of different larval stages indicate that, with the exception of becoming relatively thinner, PAcartilages appear to grow isometrically or close to it in both salamanders and frogs (Fig. 1 in Rose, 2009, 2015). Nonetheless, a quantitative approach is direly needed to expose which cartilages and which species depart from isometric growth and how they do so. Isometric growth implies that all species-specific aspects of PA cartilage shape and, by extension, all interspecific differences are established in embryonic patterning. Allometric growth implies that interspecific differences can also arise during growth and in either a size-dependent or size-independent fashion. On one hand, isometric growth is theoretically constraining in that it does not allow for shape changes to accommodate changing functional demands. On the other hand, it would ensure that cartilages finish growth and start metamorphosis at fixed shapes, which could be important for maintaining the functional integrity of metamorphic ontogenies (see below).

\section{How do pharyngeal arch cartilages grow and change shape?}

Unlike most parts of the chondrocranium, which grow as sheets alongside sense organs and regions of brain, PA cartilages grow on their own and as rods, bars and plates. Whereas growth of the chondrocranium is subject to two sources of biomechanical loading (stretching of internal surfaces by the growth of sense organs and brain regions and pulling on external surfaces by the contraction of muscles), the growth of PA cartilages is subject only to the latter. Unlike bone, cartilage is nonvascular and its outer layer of flattened, undifferentiated cells (perichondrium) seals it off from all other tissues. Also, whereas bone grows only by the deposition of matrix and mineral along external surfaces (accretional growth), cartilage grows by the division, death, matrix secretion and changes in size and shape of chondrocytes in the center of the tissue (interstitial growth) (Hall, 2005, Rose, 2009). Although cartilage might also grow on its surface by recruiting chondrocytes from the perichondrium (appositional growth), the occurrence of this process in amphibians is unclear. Histological and transmission electron micrograph descriptions of larval PAelements do not report zones of small cells inside the perichondrium (de Jongh, 1968, Sedra and Michael, 1957, Thomson, 1986, Thomson, 1987), which would be expected (but is not definitive evidence) of chondrocytes being recruited in this manner.

With the exception of ceratobranchial replacement in plethodontid salamanders (Alberch and Gale, 1986), the cellular basis of how PA cartilages are transformed from larval shapes, sizes and orientations into postmetamorphic ones is poorly understood. On 
A

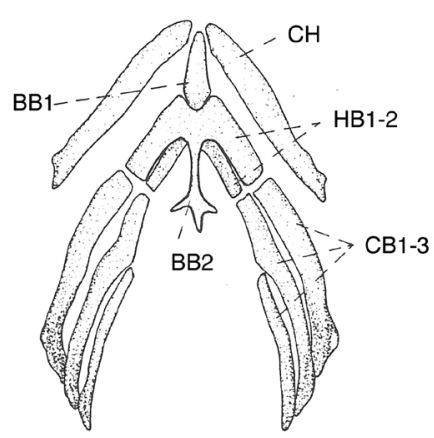

D

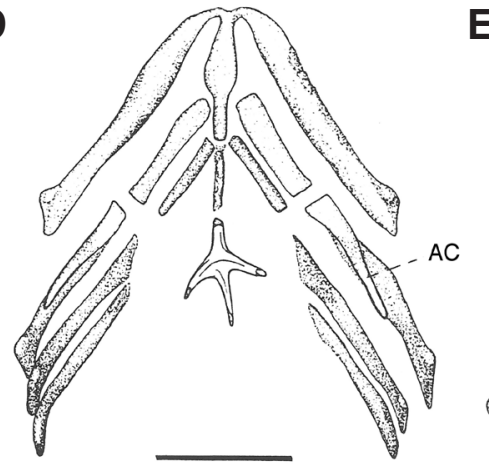

B

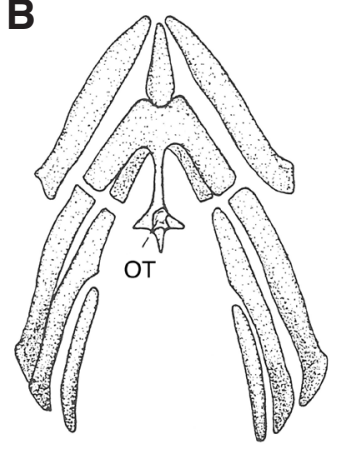

E
C
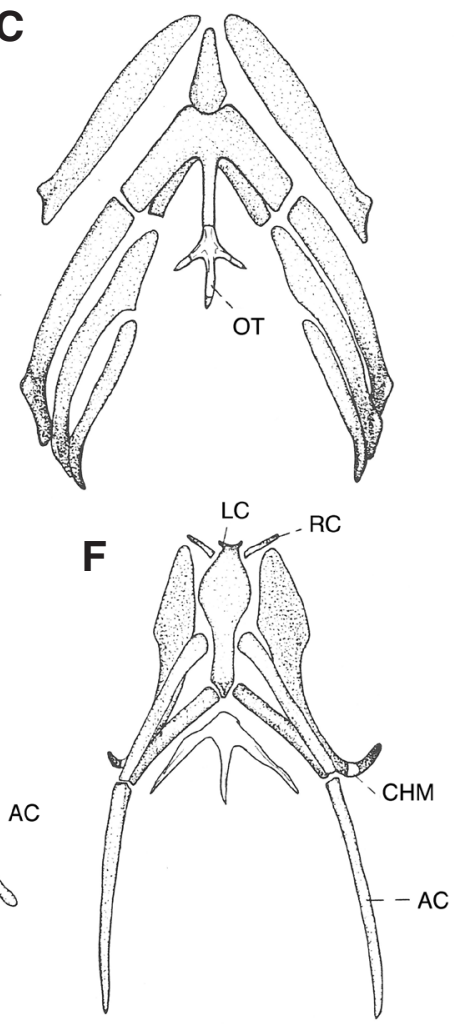

Fig. 4. Drawings of ventral views of the dissected, skeletally stained pharyngeal arch skeletons of the plethodontid salamander Eurycea bislineata at early (A), mid (B) and late larval (C) and early (D), mid (E) and postmetamorphic (F) stages. Stippled tissue is cartilage, cross-hatched tissue is bone, scale bar is $1.6 \mathrm{~mm}$ for $(A, B)$ and $2 \mathrm{~mm}$ for (C-F). AC, adult ceratobranchial; CHM ceratohyal mineralization; $L C$, lingual cartilage; OT, os thyroideum; $R C$, radial cartilage; see Fig. 1 for other terms. Reprinted with permission of the author from Rose (1995a); terms have been changed to be consistent with the terminology in other figures. the basis of anatomical, morphometric and histological descriptions, Rose (2009) hypothesized three cellular pathways: 1) de novo condensation to add new parts onto existing cartilages, 2) reshaping and resizing cartilages by spatially integrated mixes of cell division, death and matrix secretion, and 3) reshaping and resizing cartilages by spatially segregated mixes of cell division, death and matrix secretion.

Ceratobranchial replacement (Fig. 4) appears to be an extreme manifestation of the first pathway. Cells for the adult cartilage appear to derive from a small portion of the perichondrium of the larval cartilage, which also serves as a base for their condensation and for growth and differentiation of the new cartilage, which ultimately replaces the resorbing larval cartilage (Alberch and Gale, 1986). When the process is induced precociously, the condensation arises separately from the larval element, which persists in a shortened form (Rose, 1995b). Other new elements or cartilage additions that appear to arise in this way include the frog tympanic ring and columella, the cells for which appear to derive from the perichondrium of a resorbing part of the palatoquadrate (Barry, 1956, van der Westhuizen, 1961); the posterior hook and lateral plate-like additions to salamander ceratohyals; the posterior radial cartilages of salamanders and the two or three paired processes of the hyoglossal skeleton in frogs. Efforts to label the larval portions of adult cartilages in Xenopus suggest that both ends of the adult Meckels cartilage are also added on in this manner (Kerney et al., 2012b). Whether progenitor cells are always recruited from the perichondria of resorbing cartilages or can also derive from uncondensed populations of former neural crest cells is unclear.

Distinguishing between the second and third pathways is subjective and depends on the scale and pattern of cell behaviors within larval cartilages and whether the perichondrium stays intact. In the second pathway, cells simply become rearranged to transform, for example, a thick, short cartilage into a longer, thinner one with a slightly different shape. In the third pathway, cells on the periphery of the larval cartilage die and those in the center undergo morphogenesis to form a smaller cartilage with a different shape. Both pathways require that larval cartilages have relatively little matrix and undergo cell division to produce smaller cells that can either be rearranged to reshape the larval cartilage or undergo morphogenesis to form a new cartilage within the resorbing larval cartilage. In contrast to Kerney et al., (2012b), histological description and careful morphometric analyses of the Meckels cartilage and ceratohyal in Xenopus (Rose, 2009, 2015) suggest that these cartilages exemplify these two pathways.

\section{How is pharyngeal arch cartilage shape controlled in growth and metamorphosis?}

The cellular basis for regulating cartilage shape in growth has so far been studied only for limb elements in mammals (Cooper et al., 2013, Farnum et al., 2008, Serrat, 2014). However, the existence of shape regulating mechanisms in amphibian cranial cartilages is supported by studies of untreated and teratogen-exposed Xenopus tadpoles (Rose, 2015, Vandenberg et al., 2012), which show that variation in cartilage shape tends to decrease with tadpole growth.

Understanding how cartilage shape is regulated in growth and metamorphosis is complicated by several factors. Amphibians have relatively large cell sizes, cartilage histology differs among elements and changes over growth and metamorphosis, and at least two of the cellular pathways for cartilage shape change (1 and 3) are qualitatively different from what happens in cartilage growth. Since growth and metamorphosis involve rounded chon- 
drocytes and flattened perichondrial cells embedded in matrix (Rose, 2009), their mechanisms for regulating shape are also likely to be qualitatively different from the patterning mechanisms of embryogenesis, though this does not preclude the pathways for shape change being specified in embryogenesis. Also, early cartilage growth appears to have very different requirements for shape regulation than later growth. Shape must be maintained in elements that initially lack a perichondrium and, judging from zebrafish PA development (Kimmel et al., 1998), might pass through stages of being one, two and three cells thick (Rose, 2009). In this scenario, in addition to cell-cell interfaces, a cell surface might contribute to first the entire circumference of a cylindrical cartilage, then one half of its circumference and eventually either a smaller portion of its surface or none at all.

Regarding the role of environmental factors, though mechanical loading affects the growth of epiphyseal growth plates and articular and condylar cartilages (Hall, 2005, Shwartz et al., 2013), to my knowledge, there are no reports of mechanically induced changes in the shapes of any PA cartilages in amphibians or fish including chondrichthyans. Amphibian PA cartilages lack the zonation of cell behaviors that defines epiphyseal growth plates (Rose, 2009) and do not generally develop raised or ridged muscle attachment surfaces (Rose, 2003), which are the characteristic signs of mechanical loading influencing bone growth. Also, cartilage lacks mineral and its vacuolate cells and hydrated, water permeable extracellular matrix produce an internal fluid pressure (Wolpert, 1981) that should make it respond to stress quite differently than bone. Cartilages that are bent or compressed by loading are likely to experience changes in fluid pressure evenly throughout the tissue. Suggestions that the growth allometries of parts of tadpole chondrocrania reflect ontogenetic changes in mechanical loading (Larson, 2002) and that intraspecific differences in these allometries arise from food differences (Larson, 2004) are difficult to test. Tadpole chondrocranial growth appears to be affected by temperature (Jorgensen and Sheil, 2008), but given the daily extremes in temperature and unpredictable seasonal changes that most temperate amphibian larvae experience, it is difficult to envision skull cartilages effecting an adaptive response to this environmental variable in the way that limb cartilages do in endotherms (Serrat, 2014).

\section{How does evolving a metamorphosis impact pharyngeal arch skeletal ontogeny?}

The association between amphibians evolving a metamorphosis and growing and transforming their larval PAskeletons as cartilage invites some consideration of causality. Cartilage appears to a better choice for evolving a metamorphosis than bone for a number of reasons. Larval amphibians gain support from buoyancy and can obviously meet the strength, flexibility and compressibility needs for their feeding and breathing movements with cartilage while avoiding the added weight, rigidity and calcium demand of bone. That bony parts of larval PA skeletons sometimes grow more slowly than cartilage might reflect either the additional strength imparted by bone or the additional cost of making it. Cartilage is also probably less energy- and time-consuming to resorb than bone. Indeed, the only bones lost at metamorphosis by frogs and salamanders are palatal and inner jaw bones and mineralized portions of larval ceratobranchials in salamanders (Rocek, 2003, Rose, 2003). However, one caecilian species flouts this hypothetical constraint by apparently making almost its entire larval PA skeleton in bone and replacing it all with new cartilage elements at metamorphosis (Wake, 1989).

A more compelling reason for why amphibian PA skeletons grow and transform as cartilage is that cartilage provides more cellular pathways for metamorphic shape change than bone. Pathways 2 and 3 rely on cell behaviors that cannot happen in bone. Throughout frogs and salamanders, only one larval bone (the vomer of salamanders) appears to be largely replaced by new bone at metamorphosis (Rocek, 2003, Rose, 2003). All others appear to use accretional growth to become larger and/or develop more prominent parts, much the way they do before and after metamorphosis.

Probably the most compelling reason for why amphibian PA skeletons grow and transform as cartilage is that cartilage is the first skeletal tissue to differentiate embryonically and the evolutionary origin of amphibian metamorphosis likely involved coordinated changes in the embryological patterning of PA cartilages and their shape regulation during growth. Changes and delays in specific aspects of embryological patterning had to occur to create cartilages with distinctly larval shapes. At the same time, larval periods of increasingly allometric growth had to transition into cellular pathways of shape change for transforming the larval cartilages into distinctly adult shapes.

How individual tissues acquired a particular cellular pathway for changing shape probably depended on the size and shape changes being selected for, as well as the histological properties required by the functions of the larval and adult cartilages. Pathway 2 allows for subtle changes in cartilage curvature, thickness and length without disrupting the structural integrity or function of the tissue. Pathway 3 contrasts by allowing a magnitude of shape change that is limited only by the extent of the accompanying size reduction, but it also requires a temporary disruption of the perichondrium and cellular fabric of the cartilage. Both pathways call for cartilage thinning, which, based on anatomical descriptions, appears to be common in many parts of the amphibian PA skeleton (Rose, 2009). Indeed, the emergence of long, curving, string-like radial cartilages from within blocky hypohyal cartilages in hynobiid and dicamptodontid salamanders (Rose, 2003) defies the classical notion that larval cartilage shape constrains the evolution of adult cartilage shape.

As exemplified by ceratobranchial replacement in the plethodontid Eurycea, the choice of pathway might also be predicated on how associated tissues are remodeled. The new adult ceratobranchial develops along with a new helically wound muscle that replaces the linear muscle used to protract the larval cartilage (Alberch and Gale, 1986). As demonstrated by Meckels cartilage in Xenopus (Rose, 2015), cartilages can be made longer, thinner and slightly more curved without having to be replaced. As demonstrated by other plethodontids like Hemidactylium and Desmognathus, ceratobranchial replacement does not always produce a noticeably longer and more curving adult cartilage (Rose, 2009). Hence, the first pathway likely evolved here to make a unique configuration of adult cartilage and muscle and not simply an adult cartilage with a new shape.

At the same time that the choice of cartilage might have created opportunities for functional diversification, the functional requirements of the PA skeleton are likely to have constrained how PA cartilages grow and change shape. Metamorphosis transforms a network of rod- and bar-like PA cartilages that are designed for 
one set of movements and loads into another network designed for very different movements and loads. Since feeding must be interrupted, selection dictates that the transformation happen as quickly as possible and precisely enough to ensure that the adult network functions efficiently and as soon as possible in the new environment. The specific pathways adopted for transforming cartilage shapes, sizes and orientations at metamorphosis are all expected to require specific starting points in order to arrive at their optimal endpoints in a coordinated fashion.

That amphibians have exceptionally variable growth and developmental rates could pose a problem in this regard. Rose (2014) lists more than twenty environmental factors that cause variation in one or both rates, and notes that Xenopus tadpoles at the start of metamorphosis exhibit more than a two-fold range in body size. The best way to guard against size-related variation in starting shapes is to stay close to isometric growth and to regulate shape as tightly as possible. This argument predicts that parts of the larval PA skeleton that contribute to functionally critical parts of the adult PA skeleton will grow isometrically and vary little in shape especially as the animal approaches metamorphosis. Parts of the chondrocranium that do not move and either disappear at metamorphosis, pass through it unchanged or serve as a framework for adding on new adult skeleton are expected to be more variable and more open to allometric growth. Both predictions are born out by the few morphometric studies currently available for tadpole skull development (Larson, 2002, Larson, 2004, Larson, 2005, Rose, 2015).

\section{How does evolving away from metamorphosis impact pharyngeal arch skeletal ontogeny?}

Direct development and paedomorphosis (meaning here the retention of the larval morphology through adulthood) in amphibians present rare opportunities to understand how skeletal development is modified in evolution because in both cases we have a pretty good idea of the primitive metamorphic skeletal ontogeny and enough of this ontogeny is retained in the derived forms to inform us about the developmental mechanisms involved in their evolution.

\section{Direct development}

Direct development, which has evolved multiple times in both frogs and plethodontid salamanders, generally involves the loss of larva-specific anatomical features, elimination of the larval growth period and the predisplacement of metamorphic changes to intra-oval development. The changes in skeletal development (Hanken et al., 1992, Kerney et al., 2007, Kerney et al., 2012a, Lynn, 1942) and evidence that the predisplacement is caused by a shift in the timing of thyroid gland activity (Callery and Elinson, 2000; Jennings and Hanken, 1998) are well described elsewhere. What is interesting here are the differences in how direct developing salamanders and frogs have diverged from their primitive metamorphic ontogenies.

Comparing the direct developing plethodontid Plethodon(Kerney et al., 2012a) and the metamorphosing plethodontid Eurycea(Rose, 1995a) reveals a remarkable similarity in PA skeletal ontogeny (Fig. 4-5). Most cartilages pass through the same changes in cartilage shape, size and orientation and with the same timing relative to each other. The few differences in Plethodoninclude ceratobranchial replacement, which appears to involve a much larger portion of the larval cartilage serving as a template for forming the adult cartilage, and the fourth ceratobranchial being relatively smaller and shorter lived. The metamorphic changes are similar despite happening at the end of a prolonged period of intra-ovum development in Plethodon and a multiyear larval period in Eurycea. Observations on another direct developing plethodontid, Desmognathus aeneus (Marks, 1994, Marks and Collazo, 1998), support the finding that direct
A

Fig. 5. Drawings of ventral views of the dissected, skeletally stained pharyngeal arch skeletons of the plethodontid salamander Plethodon cinereus at six stages before hatching (A-F) and hatching $(\mathrm{G})$ and juvenile $(\mathrm{H})$ stages. All tissue is cartilage with the exception of the OT los thyroideum); scale bars are $0.5 \mathrm{~mm}$; see Figs. 1 and 4 for additional terms. Reprinted with permission of the author from Kerney at al. (2012a); terms have been changed to be consistent with terminology used in this paper.

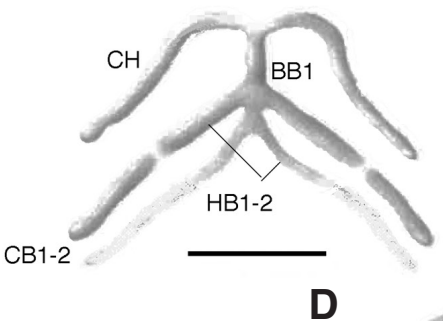

B

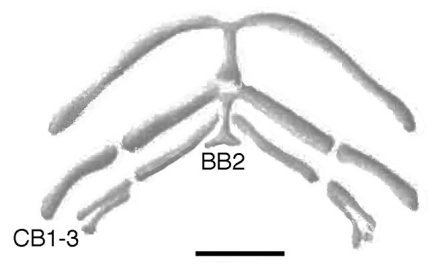

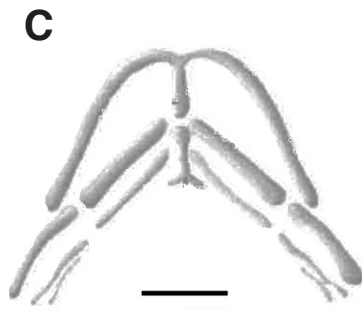

$F$

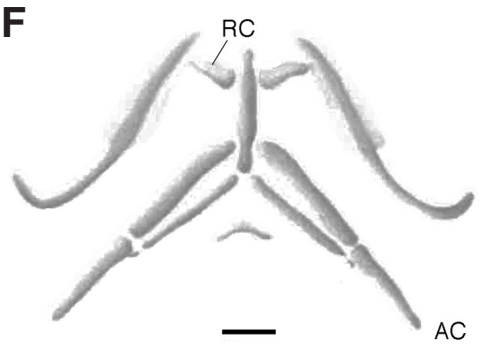

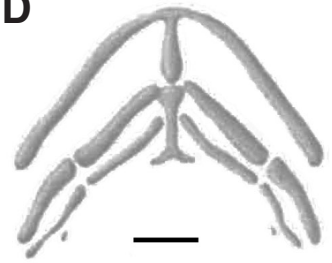

G
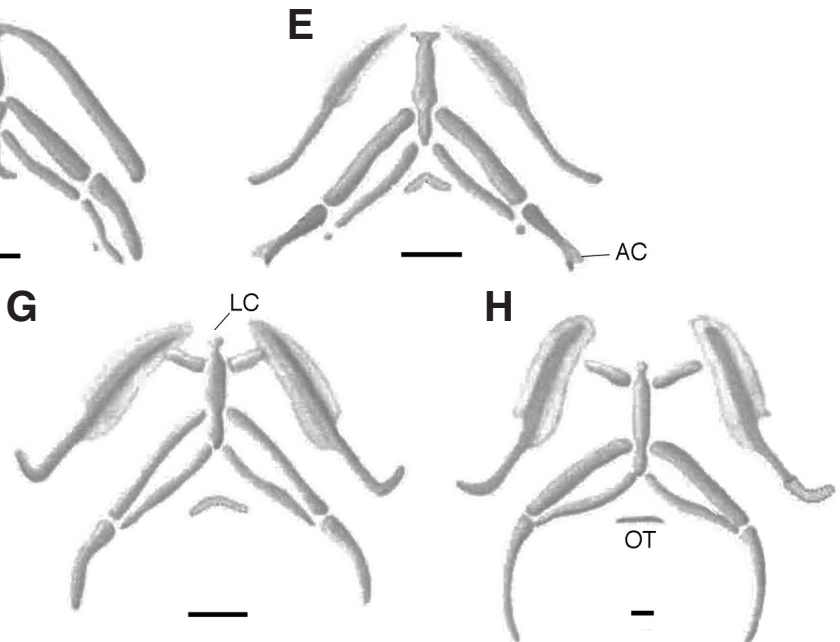
developing salamanders have generally eliminated larval growth and merged embryonic and metamorphic development into one prolonged developmental period before hatching. Bolitoglossine salamanders appear to have progressed further than other direct developing salamanders by modifying the shape and size of certain adult PA cartilages to allow for much greater tongue projection (Wake, 1982, Wake and Roth, 1989). The second hypobranchial is now more robust than the first hypobranchial and the first ceratobranchial is extremely elongated. While these changes appear linked to the losses of lungs and larval period, how embryonic and metamorphic patterning were altered to produce them awaits a detailed study of prehatching development.

Direct developing frogs also appear to have evolved beyond the elimination of larval growth by additionally deleting late embryonic and early metamorphic stages of frog development (Hanken et al., 1992, Kerney et al., 2007). The lower jaw, palatoquadrate and branchial arch skeletons all appear at what are generally recognized as midmetamorphic shapes, sizes and orientations in metamorphosing frogs, albeit without the fine details like gill rays, and they complete the remaining metamorphic shape changes while inside the egg. This kind of evolutionary change differs from how cartilages are normally lost in vertebrate evolution. For example, considering the tail vertebrae in humans (Fallon and Simandl, 1978) and the peripheral phalanges of mammals (Cooper et al., 2014) and skinks (Shapiro et al., 2003) that have evolved digit reduction, the cells of these elements appear to die or be recruited by other elements just before they would normally differentiate into cartilage. In contrast to being directed to new fates, the cranial neural crest cells of direct developing frogs appear to condense and differentiate directly into midmetamorphic shaped cartilages (Kerney et al., 2010).

That early shape changes can be deleted without affecting later ones demonstrates that the patterning of late metamorphic shape changes does not depend on cells having progressed through earlier shape changes. Cellular pathways like ceratobranchial replacement, which presumably evolved to change the shape of large, differentiated cartilages, appear to become less conspicuously expressed as embryonic and metamorphic development merge and be eventually subsumed by precondensation cell behaviors. If embryonic and metamorphic patterning events are controlled by upstream and downstream components of the same gene cascades, direct development argues for the ability to excise middle portions of this cascade without affecting later portions or any tissue interactions involved in forming adult morphology. Why this mechanistic flexibility has not been exploited for greater diversification of adult PA skeletons is the real mystery. Although bolitoglossines appear to exemplify evolutionary divergence in embryonic patterning that affects adult morphology, I would argue that most cases of direct development are really opportunities to ask how and why the development of adult morphology is constrained despite the loss of patterning steps to create earlier morphology.

\section{Paedomorphosis}

Paedomorphosis has evolved frequently in two large families of salamanders (salamandrids and ambystomatids), infrequently and rarely in two other large families (plethodontids and hynobiids) and frequently and not at all in two small families (dicamptodontids and rhyacotritonids) (Denoel et al., 2005, Petranka, 1998, Rose, 1999). It is exclusive and probably ancestral in four other small families (cryptobranchids, sirenids, amphiumids and proteids).

Hormonally speaking, salamander species can exhibit one of three kinds of paedomorphosis: 1) some individuals or populations metamorphose naturally and others do not but all can be induced to metamorphose by applying thyroid hormone (TH), 2) no individuals metamorphose naturally but all can be induced to metamorphose at a morphological level, and 3) no individuals can be induced to metamorphose to a recognizable extent, though certain morphological, physiological or cell-level changes might still be inducible or occur naturally (Johnson and Voss, 2013, Rose, 1999). As the descriptions suggest, these three types of paedomorphosis can be interpreted as evolutionary grades that species progress through by accumulating mutations that make them reduce or cease $\mathrm{TH}$ production and then eventually lose their tissue sensitivity to $\mathrm{TH}$. Based on the limited data available for $\mathrm{TH}$ production and tissue sensitivity in paedomorphic forms - much of which is of questionable relevance as it comes from adults rather than larvae (Johnson and Voss, 2013, Rose, 1999) - most salamandrids and ambystomatids and some plethodontids are at the first grade, some plethodontids and ambystomatids are at the second, and cryptobranchids, sirenids, amphiumids and proteids are at the third.

Morphologically speaking, however, salamander metamorphosis and paedomorphosis come in several ontogenetic patterns, which point to taxon- and ecology-specific pathways of life history evolution (Rose, 1996, Rose, 1999). All metamorphosing salamanders transform their PA skeletons synchronously with gill and tailfin loss at the end of a larval period that is several months or years long. However, there are family-level differences in the timing of other shared postembryonic changes in the skull and skin, including the loss of Leydig cells and appearance of multicellular skin glands. Whereas most metamorphosing salamanders carry out some skull and skin changes during the larval growth period, metamorphosing plethodontids delay all postembryonic changes to the time of gill loss. Paedomorphosis in both forms typically involves the arrest of skull and skin development just before the stage at which gill loss is expected to occur. Thus, whereas nonplethodontid paedomorphs have partially developed nasal skeletons, small maxilla bones and a partially transformed palate, plethodontid paedomorphs lack these features as adults.

Cryptobranchids, sirenids and proteids differ from the paedomorphs in other families by showing a gradation in the amount of larval and metamorphic development that they retain (Rose, 1999). At one extreme, the proteid Necturus develops only skin glands and an incomplete nasal capsule soon after hatching, and the other extreme, the cryptobranchid Andrias completes most of the postembryonic changes exhibited by metamorphosing salamanders and does so over a multiyear larval period that culminates in gill resorption and ceratobranchial reduction. Amphiumids stand apart in retaining most postembryonic changes including gill resorption but not ceratobranchial reduction and carrying them out during or soon after embryonic development.

The postembryonic skull and skin changes shared by most salamanders show a surprising correspondence between their differences in timing and extent of occurrence across the class and their differences in TH sensitivity in metamorphosing plethodontids (Rose, 1995c, Rose, 1996, Rose, 1999). The more sensitive events are generally more widespread in phylogeny and occur earlier in ontogeny. This correspondence suggests that the gradual developmental pattern of metamorphosing nonplethodontids is regulated 
by a gradual increase in TH throughout larval and metamorphic periods as in frogs, and the more abrupt pattern of plethodontids results from an abrupt surge in $\mathrm{TH}$ at the end of the larval period. Paedomorphosis in both groups is generally consistent with $\mathrm{TH}$ production terminating at the end of the larval period. In contrast, the developmental patterns of cryptobranchids, sirenids, and proteids are more consistent with a gradual $\mathrm{TH}$ profile becoming attenuated to varying degrees before the tissues lose their $\mathrm{TH}$ sensitivity. Amphiumids bear the least resemblance to the ancestral developmental pattern and their derivation appears to have involved changes in both timing and level of TH activity.

Paedomorphosis is generally associated with springs, porous streambeds and caves in plethodontids and with ponds and lower temperature in the other families of metamorphosing salamanders (Bonett and Chippindale, 2006, Denoel et al., 2005, Johnson and Voss, 2013). In contrast, cryptobranchids, sirenids, proteids and amphiumids live in large, permanent bodies of water, i.e., rivers, lakes, swamps and floodplains (Petranka, 1998).

The TH truncation and attenuation pathways for evolving different forms of paedomorphosis cannot be tested directly since larval $\mathrm{TH}$ levels in metamorphosing forms are often below detectable levels and cryptobranchids, sirenids, amphiumids and proteids appear to have largely abandoned TH mediation of their postembryonic skeletal development (Johnson and Voss, 2013, Rose, 1999). Nonetheless, some correlations can be drawn between how paedomorphosis appears to evolve and changes in PA skeletal development. Judging from anatomical descriptions (Rose, 2003), truncating $\mathrm{TH}$ production to arrest larval development before gill loss is not associated with changes in the embryonic patterning or larval growth trajectories of PA cartilages. In contrast, attenuating $\mathrm{TH}$ levels to eliminate the less sensitive components of larval and metamorphic development is associated with unusually thick PA cartilages in the proteid Necturus, unusually short ceratobranchials in sirenids and amphiumids (Fig. $1 \mathrm{E}-\mathrm{F}$ ), and the postembryonic addition and elaboration of more circular, less rod-like anterior PA cartilages (hypohyals, basihyals and anterior basibranchials) in amphiumids and cryptobranchids (Fig. 1 F-G, Rose, 2003). The attenuation pathway is also associated with animals growing to exceptionally large sizes, growing allometrically to produce more derived body and skull shapes, and losing or reducing limbs. Regardless of exactly how paedomorphosis evolved in the move to large, permanent water bodies, this kind of paedomorphosis appears to have allowed salamanders more freedom to modify the embryonic and postembryonic patterning of their PA skeleton. It unfortunately did not allow for any adaptive radiation so there was not much ensuing diversification to learn from.

\section{Concluding remarks}

If it were possible to map the morphospace occupied by the PA cartilages of all stages of all species of either frog or salamander and to observe the shape variation contributed by embryonic and metamorphic patterning and larval and postmetamorphic growth, I would predict that the biggest spread would be between the contributions from embryonic and metamorphic patterning. I would also predict that the intraspecific variation between these two components is generally greater than the interspecific variation produced by either component alone. In other words, having evolved their biphasic patterns of PA skeletal development, frogs and salamanders appear to have been locked into relatively conservative ontogenies with limited opportunity for interspecific variation to arise from embryonic and metamorphic patterning or allometric growth. I have presented pattern- and description-based arguments for how the properties of cartilage might have facilitated the evolution of metamorphic ontogenies in amphibians and also imposed limits on how their PA skeletons could be modified in ontogeny and evolution. Testing these arguments awaits more mechanistic and allometric study of the growth and shape change of PA cartilages in amphibians as well as in nonmetamorphosing vertebrates that grow their PA skeletons primarily or exclusively in cartilage, e.g., lungfish, sturgeons, chondrichthyans, and many larval fishes.

\section{Acknowledgments}

Thanks to Carlos Infante, John Reiss, and David McLeod for the photos or gifts of specimens and to Tyler Square, David Jandzik, and Daniel M. Medeiros for the two photos of Sox9 whole mount in situs.

\section{References}

ABZHANOV, A., KUO, W.P., HARTMANN, C., GRANT, B.R., GRANT, P.R. and TABIN, C.J. (2006). The calmodulin pathway and evolution of elongated beak morphology in Darwin's finches. Nature 442: 563-567.

ABZHANOV, A., PROTAS, M., GRANT, B.R., GRANT, P.R. and TABIN, C.J. (2004) Bmp4 and morphological variation of beaks in Darwin's finches. Science 305: 1462-1465.

ALBERCH, P. and GALE, E.A. (1986). Pathways of cytodifferentiation during the metamorphosis of the epibranchial cartilage in the salamander, Eurycea bislineata. Dev Biol 117: 233-244

ALEXANDER, R.M. (1994). Bones: the Unity of Form and Function. McMillan, New York.

ANDRES, G. (1949). Untersuchungen an Chimaeren von Bombinator und Triton. Entwicklung xenoplastischer Labyrinthe und Kopfganglien. I. Genetica 24: 1-148.

BARRY, T.H. (1956). The ontogenesis of the sound-conducting apparatus of Bufo augusticeps Smith. Morphologisches Jahrbuch 97: 477-544.

BONETT, R.M. and CHIPPINDALE, P.T. (2006). Streambed microstructure predicts evolution of development and life history mode in the plethodontid salamander Eurycea tynerensis. BMC Biology 4:6.

CALLERY, E.M. and ELINSON, R.P. (2000). Thyroid hormone-dependent metamorphosis in a direct developing frog. Proc. Natl. Acad. Sci. USA 97: 2615-2620.

CANNATELLA, D. (1999). Architecture: cranial and axial musculoskeleton. In Tadpoles, (ed. MCDIARMID, R. W. and ALTIG, R.). University of Chicago Press, Chicago, pp.5 2-91.

CARROÑO, C.A. and NISHIKAWA, K.C. (2010). Aquatic feeding in pipid frogs: The use of suction for prey capture. J Exp Biol 213: 2001-2008.

CERNY, R., MEULEMANS, D., BERGER, J., WILSCH-BRAUNINGER, M., KURTH, T., BRONNER-FRASER, M. and EPPERLEIN, H.H. (2004). Combined intrinsic and extrinsic influences pattern cranial neural crest migration and pharyngeal arch morphogenesis in axolotl. Dev Biol 266: 252-269

COOPER, K.L., OH, S., SUNG, Y., DASARI, R.R., KIRSCHNER, M.W. and TABIN, C.J. (2013). Multiple phases of chondrocyte enlargement underlie differences in skeletal proportions. Nature 495: 375-378.

COOPER, K.L., SEARS, K.E., UYGUR, A., MAIER, J., BACZKOWSKI, K.S., BROSNAHAN, M., ANTCZAK, D., SKIDMORE, J.A. and TABIN, C.J. (2014). Patterning and post-patterning modes of evolutionary digit loss in mammals. Nature 511: 41-45.

DE BEER, G.R. (1937). The Development of the Vertebrate Skull. Oxford University Press, Oxford

DE JONGH, H.J. (1968). Functional morphology of the jaw apparatus of larval and metamorphosing Rana temporaria L. Netherlands J Zool 18: 1-103.

DEBAN, S.M. (2003). Constraint and convergence in the evolution of salamande feeding. In Vertebrate Biomechanics and Evolution, (ed. BELS, V. L.GASC, J.-P. and CASINOS, A.). BIOS Scientific Publishers, Oxford, pp.161-178.

DEBAN, S.M. and OLSON, W.M. (2002). Biomechanics: Suction feeding by a tiny 
predatory tadpole. Nature 420: 41.

DEBAN, S.M. and WAKE, D.B. (2000). Aquatic feeding in salamanders. In Feeding in Tetrapod Vertebrates: Form, Function, Phylogeny, (ed. SCHWENK, K.). Academic press, San Diego, pp.65-94.

DENOEL, M., JOLY, P. and WHITEMAN, H.H. (2005). Evolutionary ecology of facultative paedomorphosis in newts and salamanders. Biol Rev Cam Phil Soc 80: 663-671.

DEPEW, M.J., LUFKIN, T. and RUBENSTEIN, J.L. (2002). Specification of jaw subdivisions by Dlx genes. Science 298: 381-385.

ERICSSON, R., CERNY, R., FALCK, P. and OLSSON, L. (2004). Role of cranial neural crest cells in visceral arch muscle positioning and morphogenesis in the Mexican axolotl, Ambystoma mexicanum. Dev Dyn 231: 237-247.

ERICSSON, R., ZIERMANN, J.M., PIEKARSKI, N., SCHUBERT, G., JOSS, J. and OLSSON, L. (2009). Cell fate and timing in the evolution of neural crest and mesoderm development in the head region of amphibians and lungfishes. Acta Zoologica 90: 264-272.

FALCK, P., HANKEN, J. and OLSSON, L. (2002). Cranial neural crest emergence and migration in the Mexican axolotl (Ambystoma mexicanum). Zoology 105: 195-202.

FALLON, J.F. and SIMANDL, B.K. (1978). Evidence of a role for cell death in the disappearance of the embryonic human tail. Am J Anat 152: 111-129.

FARNUM, C.E., TINSLEY, M. and HERMANSON, J.W. (2008). Postnatal bone elongation of the manus versus pes: Analysis of the chondrocytic differentiation cascade in Mus musculus and Eptesicus fuscus. Cells Tissues Organs 187: 48-58.

GOODRICH, E.S. (1930). Studies on the Structure and Development of Vertebrates. Macmillan, London.

HALL, B.K. (2005). Bones and Cartilage, Developmental and Evolutionary Skeletal Biology. Elsevier Academic Press, San Diego.

HANDRIGAN, G.R. and WASSERSUG, R.J. (2007). The anuran Bauplan: A review of the adaptive, developmental, and genetic underpinnings of frog and tadpole morphology. Biol Rev 82: 1-25.

HANKEN, J., KLYMKOWSKY, M.W., SUMMERS, C.H., SEUFERT, D.W. and INGEBRIGTSEN, N. (1992). Cranial ontogeny in the direct-developing frog, Eleutherodactylus coqui (Anura: Leptodactylidae), analyzed using whole-mount immunohistochemistry. J Morphol 211: 95-118.

JENNINGS, D.H. and HANKEN, J. (1998). Mechanistic basis of life history evolution in anuran amphibians: Thyroid gland development in the direct-developing frog, Eleutherodactylus coqui. Gen Comp Endocrinol 111: 225-232.

JOHNSON, C.K. and VOSS, S.R. (2013). Salamander paedomorphosis: Linking thyroid hormone to life history and life cycle evolution. Curr Topics Dev Biol 103: 229-258.

JORGENSEN, M.E. and SHEIL, C.A. (2008). Effects of temperature regime through premetamorphic ontogeny on shape of the chondrocranium in the American Toad, Anaxyrus americanus. Anat Rec 291: 818-826.

KERNEY, R., GROSS, J.B. and HANKEN, J. (2010). Early cranial patterning in the direct-developing frog Eleutherodactylus coqui revealed through gene expression. Evol Dev 12: 373-382.

KERNEY, R., MEEGASKUMBURA, M., MANAMENDRA-ARACHCHI, K. and HANKEN, J. (2007). Cranial ontogeny in Philautus silus (Anura: Ranidae: Rhacophorinae) reveals few similarities with other direct-developing anurans. J Morpho/268:715-725.

KERNEY, R.R., BLACKBURN, D.C., MULLER, H. and HANKEN, J. (2012a). Do larval traits re-evolve? Evidence from the embryogenesis of a direct-developing salamander, Plethodon cinereus. Evolution 66: 252-262.

KERNEY, R.R., BRITTAIN, A.L., HALL, B.K. and BUCHHOLZ, D.R. (2012b). Cartilage on the move: Cartilage lineage tracing during tadpole metamorphosis. Dev Growth Differ. 54: 739-752.

KIMMEL, C.B., MILLER, C.T., KRUZE, G., ULLMANN, B., BREMILLER, R.A., LARISON, K.D. and SNYDER, H.C. (1998). The shaping of pharyngeal cartilages during early development of the zebrafish. Dev Biol 203: 245-63.

LARSON, P.M. (2002). Chondrocranial development in larval Rana sylvatica (Anura: Ranidae): Morphometric analysis of cranial allometry and ontogenetic shape change. J Morphol 252: 131-144.

LARSON, P.M. (2004). Chondrocranial morphology and ontogenetic allometry in larval Bufo americanus (Anura, Bufonidae). Zoomorphology 123: 95-106.

LARSON, P.M. (2005). Ontogeny, phylogeny, and morphology in anuran larvae: Morphometric analysis of cranial development and evolution in Rana tadpoles (Anura: Ranidae). J Morphol 264: 34-52.
LYNN, W.G. (1942). The embryology of Eleutherodactylus nubicola, an anuran which has no tadpole stage. Carnegie Instit Washington Contrib Embryol 541: 27-62.

MARKS, S.B. (1994). Development of the hyobranchial apparatus in Desmognathus aeneus, a direct developing salamander. J Morphol 220: 371.

MARKS, S.B. and COLLAZO, A. (1998). Direct development in Desmognathus aeneus (Caudata: Plethodontidae): A staging table. Copeia 1998: 637-648.

MILLER, C.T., YELON, D., STAINIER, D.Y. and KIMMEL, C.B. (2003). Two endothelin 1 effectors, hand2 and bapx1, pattern ventral pharyngeal cartilage and the jaw joint. Development 130: 1353-65.

NISHIKAWA, K.C. (2000). Feeding in frogs. In Feeding in Tetrapod Vertebrates: Form, Function, Phylogeny, (ed. SCHWENK, K.). Academic press, San Diego, pp.117-147.

OLSSON, L. and HANKEN, J. (1996). Cranial neural-crest migration and chondrogenic fate in the oriental fire-bellied toad Bombina orientalis: Defining the ancestral pattern of head development in anuran amphibians. J Morphol 229: 105-120.

PASQUALETTI, M., ORI, M., NARDI, I. and RIJLI, F.M. (2000). Ectopic Hoxa2 induction after neural crest migration results in homeosis of jaw elements in Xenopus. Development 127: 5367-78.

PETRANKA, J.W. (1998). Salamanders of the United States and Canada. Smithsonian Institution Press, Washington.

PUGENER, L.A., MAGLIA, A.M. and TRUEB, L. (2003). Revisiting the contribution of larval characters to an analysis of phylogenetic relationships of basal anurans. Zool J Linnean Soc 139: 129-155.

PUSEY, H.K. (1938). Structural changes in the anuran mandibular arch during metamorphosis, with reference to Rana temporaria. Quart J Microsc Sci 80: 479-552.

RIDEWOOD, W.G. (1899). On the hyobranchial skeleton and larynx of the new aglossal toad, Hymenochirus boettgeri. J Linn Soc Zool 27: 454-460.

ROCEK, Z. (2003). Larval development and evolutionary origin of the anuran skull. In Amphibian Biology, Vol. 5. Osteology, (ed. HEATWOLE, H. and DAVIES, M.). Surrey Beatty and Son Pty. Ltd., Chipping Norton, Australia, pp.1877-1995.

ROSE, C.S. (1995a). Skeletal morphogenesis in the urodele skull: I. Postembryonic development in the Hemidactyliini (Amphibia: Plethodontidae). J Morphol 223 125-148.

ROSE, C.S. (1995b). Skeletal morphogenesis in the urodele skull: II. Effect of developmental stage in TH-induced remodelling. J Morphol 223: 149--166.

ROSE, C.S. (1995c). Skeletal morphogenesis in the urodele skull: III. Effect of hormone dosage in TH-induced remodelling. J Morphol 223: 243--261.

ROSE, C.S. (1996). An endocrine-based model for developmental and morphogenetic diversification in metamorphic and paedomorphic urodeles. J Zool 239: 253-284.

ROSE, C.S. (1999). Hormonal control in larval development and evolution - Amphibians. In The Origin and Evolution of Larval Forms, (ed. HALL, B. K. and WAKE, M. H.). Academic Press, San Diego, pp.167-216.

ROSE, C.S. (2003). The developmental morphology of salamander skulls. In Amphibian Biology, Vol. 5. Osteology, (ed. HEATWOLE, H. and DAVIES, M.). Surrey Beatty and Son Pty. Ltd., Chipping Norton, Australia, pp.1686-1783.

ROSE, C.S. (2009). Generating, growing and transforming skeletal shape: Insights from amphibian pharyngeal arch cartilages. BioEssays 31: 287-299.

ROSE, C.S. (2014). Caging, but not air deprivation, slows tadpole growth and development in the amphibian Xenopus laevis. J Exp Zool 321A: 365-375

ROSE, C.S. (2015). Deconstructing cartilage shape and size into contributions from embryogenesis, metamorphosis, and tadpole and frog growth. J Anat 226: 575595 (doi: 10.1111/joa 12303)

RYERSON, W.G. and DEBAN, S.M. (2010). Buccal pumping mechanics of Xenopus laevis tadpoles: Effects of biotic and abiotic factors. J Exp Biol 213: 2444-2452.

SADAGHIANI, B. and THIÉBAUD, C.H. (1987). Neural crest development in the Xenopus laevis embryo, studied by interspecific transplantation and scanning electron microscopy. Dev Biol 124: 91-110.

SANTAGATI, F. and RIJLI, F.M. (2003). Cranial neural crest and the building of the vertebrate head. Nat Rev Neurosci 4: 806-818.

SCHNEIDER, R.A. and HELMS, J.A. (2003). The cellular and molecular origins of beak morphology. Science 299: 565-568.

SEDRA, S.N. and MICHAEL, M.I. (1957). The development of the skull, visceral arches, larynx and visceral muscles of the South African clawed toad, Xenopus laevis (Daudin) during the process of metamorphosis (from stage 55 to stage 66). Verhandelingen der Koninklijke Nederlandse Akademie van Wetenschappen, 
Afdeling Natuurkunde. Tweede Reeks 51: 1-80.

SERRAT, M.A. (2014). Environmental temperature impact on bone and cartilage growth. Comprehen Physiol 4: 621-655.

SHAPIRO, M.D., HANKEN, J. and ROSENTHAL, N. (2003). Developmental basis of evolutionary digit loss in the Australian lizard Hemiergis. $J$ Exp Zool Part B: Mol Dev Evol 297: 48-56

SHWARTZ, Y., BLITZ, E. and ZELZER, E. (2013). One load to rule them all: Mechanical control of the musculoskeletal system in development and aging. Differentiation 86: 104-111.

SQUARE, T., JANDZIK, D., CATTELL, M., COE, A., DOHERTY, J. and MEDEIROS, D.M. (2015). A gene expression map of the larval Xenopus laevis head reveals developmental changes underlying the evolution of new skeletal elements. Dev Biol 397: 293-304.

THOMSON, D.A.R. (1986). Meckel's cartilage in Xenopus laevis during metamorphosis: a light and electron microscope study. J Anat 149: 77-87.

THOMSON, D.A.R. (1987). A quantitative analysis of cellular and matrix changes in Meckel's cartilage in Xenopus laevis. J Anat 151: 249-254.

TUCKER, A.S. and LUMSDEN, A. (2004). Neural crest cells provide species-specific patterning information in the developing branchial skeleton. Evol Dev 6: 32-40.

VAN DER WESTHUIZEN, C.M. (1961). The development of the chondrocranium of Heleophryne purcelli Sclater with special reference to the palatoquadrate and the sound-conducting apparatus. Acta Zoologica 42: 1-72.

VANDENBERG, L.N., ADAMS, D.S. and LEVIN, M. (2012). Normalized shape and location of perturbed craniofacial structures in the Xenopus tadpole reveal an innate ability to achieve correct morphology. Dev Dyn 241: 863-878.

WAGNER, G. (1949). The significance of the neural crest in the craniofacial development of amphibian larva. Investigations on the chimeras of Triton and Bombinator. Rev Suisse Zool 56: 519-620.

WAGNER, G. (1955). Chimaerische Zahnanlagen aus Triton-Schmelzorgan und
Bombinator-Papille MitBeobachtungen über die Entwicklung von Kiemenzähnchen und Mundsinnesknospen in den Triton-Larven. JEmbryol Exp Morpho/3: 160-188.

WAKE, D.B. (1982). Functional and Developmental Constraints and Opportunities in the Evolution of Feeding Systems in Urodeles. In Environmental Adaptation and Evolution, (ed. MOSSAKOWSKI, D. and ROTH, G.). Gustav Fischer, Stuttgart, pp.51-66.

WAKE, D.B. and DEBAN, S.M. (2000). Terrestrial feeding in salamanders. In Feeding in Tetrapod Vertebrates: Form, Function, Phylogeny, (ed. SCHWENK, K.). Academic press, San Diego, pp.95-116.

WAKE, D.B. and ROTH, G. (1989). The linkage between ontogeny and phylogeny in the evolution of complex systems. In Complex Organismal Functions: Integration and Evolution in Vertebrates, Dahlem Konferenzen, (ed. WAKE, D. B. and ROTH G.). John Wiley \& Sons Ltd., New York, pp.361-377.

WAKE, M.H. (1989). Metamorphosis of the hyobranchial apparatus in Epicrionops (Amphibia: Gymnophiona: Rhinatrematidae): Replacement of bone by cartilage. Annales Sciences Naturelles Zoologie, 13 Série 10: 171-182.

WINCHESTER, S. (2012). Skulls:An Exploration of Alan Dudley's Curious Collection. Black Dog \& Leventhal Publishers, Inc., New York.

WOLPERT, L. (1981). Cartilage morphogenesis in the limb. In Cell Behaviour, (ed BELLAIRS, R.CURTIS, A. S. G. and DUNN, G.). Cambridge University Press, London, pp.359-372.

WU, P., JIANG, T.X., SHEN, J.Y., WIDELITZ, R.B. and CHUONG, C.M. (2006). Morphoregulation of avian beaks: comparative mapping of growth zone activities and morphological evolution. Dev Dyn 235: 1400-1412.

WU, P., JIANG, T.X., SUKSAWEANG, S., WIDELITZ, R.B. and CHUONG, C.M (2004). Molecular shaping of the beak. Science 305: 1465-1466.

ZIERMANN, J.M., INFANTE, C., HANKEN, J. and OLSSON, L. (2013). Morphology of the cranial skeleton and musculature in the obligate carnivorous tadpole of Lepidobatrachus laevis (Anura: Ceratophryidae). Acta Zoologica 94: 101-112. 


\section{Further Related Reading, published previously in the Int. J. Dev. Biol.}

Sexual dimorphism of AMH, DMRT1 and RSPO1 localization in the developing gonads of six anuran species

Rafal P. Piprek, Anna Pecio, Katarzyna Laskowska-Kaszub,Jacek Z. Kubiak and Jacek M. Szymura

Int. J. Dev. Biol. (2013) 57: 891-895

Dual embryonic origin of the hyobranchial apparatus in the Mexican axolotl (Ambystoma mexicanum)

Asya Davidian and Yegor Malashichev

Int. J. Dev. Biol. (2013) 57: 821-828

Clonal analyses in the anterior pre-placodal region: implications for the early lineage bias of placodal progenitors

Sujata Bhattacharyya and Marianne E. Bronner

Int. J. Dev. Biol. (2013) 57: 753-757

Amphibian interorder nuclear transfer embryos reveal conserved embryonic gene transcription, but deficient DNA replication or chromosome segregation

Patrick Narbonne and John B. Gurdon

Int. J. Dev. Biol. (2012) 56: 975-986

Origins of $\mathrm{Cdx} 1$ regulatory elements suggest roles in vertebrate evolution

Stephen J. Gaunt and Yu-Lee Paul

Int. J. Dev. Biol. (2011) 55: 93-98

Reptile scale paradigm: Evo-Devo, pattern formation and regeneration

Cheng Chang, Ping Wu, Ruth E. Baker, Philip K. Maini, Lorenzo Alibardi and Cheng-Ming Chuong

Int. J. Dev. Biol. (2009) 53: 813-826

Proteomics analysis of regenerating amphibian limbs: changes during the onset of regeneration

Michael W. King, Anton W. Neff and Anthony L. Mescher

Int. J. Dev. Biol. (2009) 53: 955-969

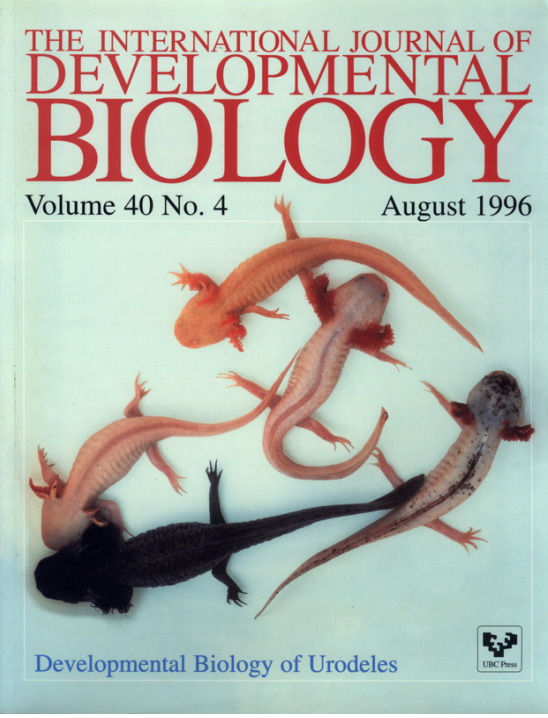

5 yr ISI Impact Factor $(2013)=2.879$
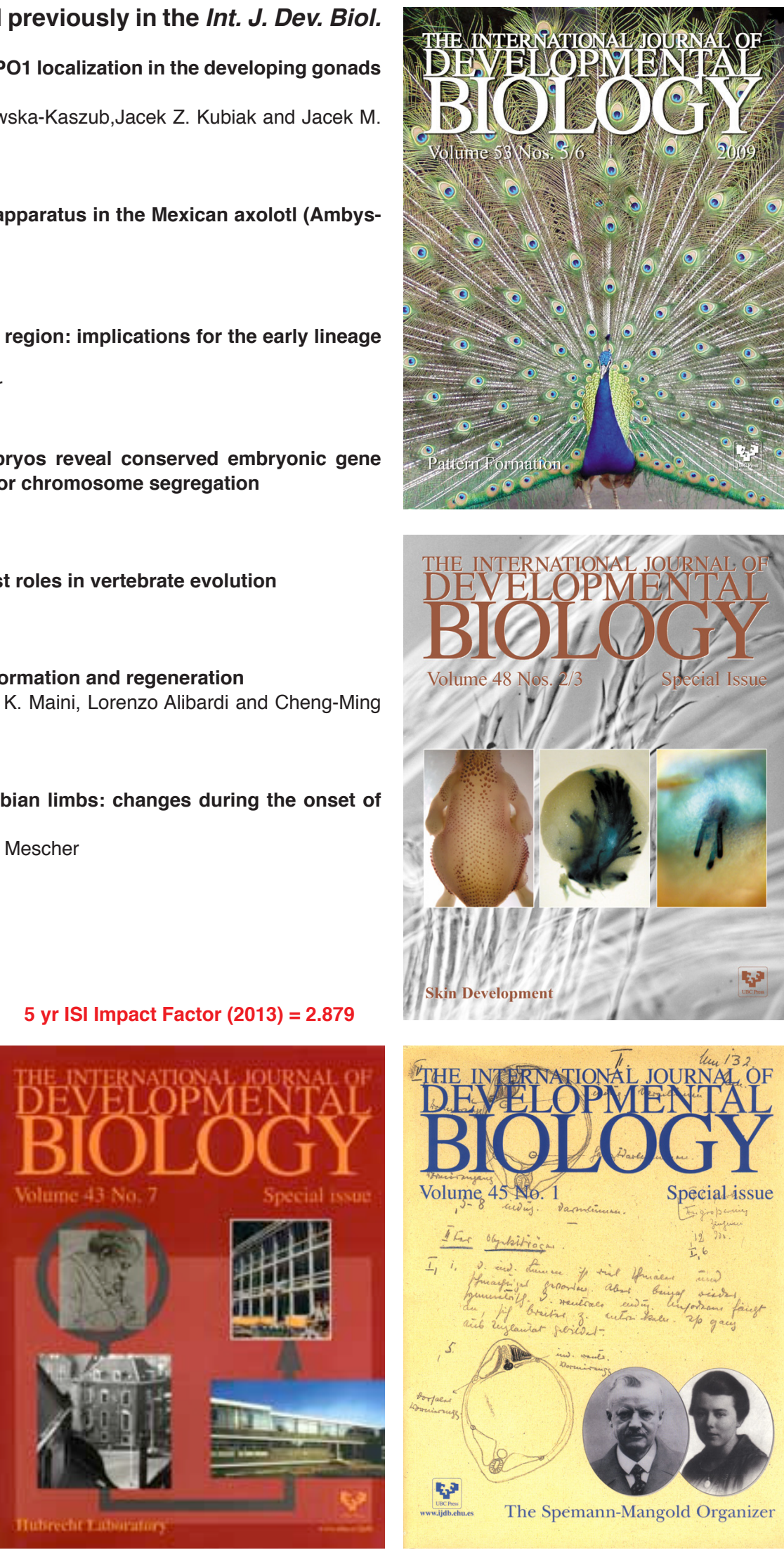

Volume 45 No. 1

Special issue
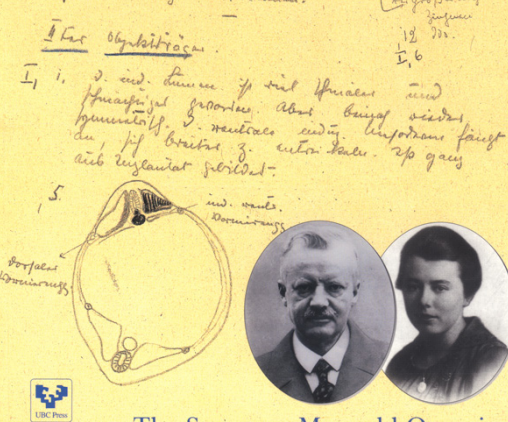

5

The Spemann-Mangold Organizer 